\title{
INVESTIGATION OF TECHNOLOGICAL PROPERTIES OF POWDER OF EGGPLANTS
}

\author{
Oksana Dzyundzya \\ Department of hotel and restaurant and tourist business \\ Kherson State University \\ 27 Universitetska str., Kherson, Ukraine, 73000 \\ Dzokvaok@gmail.com \\ Valentyna Burak \\ Department of Food Engineering \\ Kherson State Agricultural University \\ 27 Universitetska str., Kherson, Ukraine, 73000 \\ Alexander Averchev \\ Department of Agriculture \\ Kherson State Agricultural University \\ 27 Universitetska str., Kherson, Ukraine, 73000 \\ Natalya Novikova \\ Department of Food Engineering \\ Kherson State Agricultural University \\ 27 Universitetska str., Kherson, Ukraine, 73000 \\ Irina Ryapolova \\ Department of Food Engineering \\ Kherson State Agricultural University \\ 27 Universitetska str., Kherson, Ukraine, 73000 \\ Artem Antonenko \\ Department of hotel and catering business \\ Kyiv National University of Culture and Arts \\ 36 Konovaltsya str., Kyiv, Ukraine, 01133 \\ Tetiana Brovenko \\ Department of hotel and restaurant business \\ Kyiv National University of Culture and Arts \\ 36 Konovaltsya str., Kyiv, Ukraine, 01133 \\ Myroslav Kryvoruchko \\ Department of engineering and technical disciplines \\ Kyiv National University of Trade and Economics \\ 19 Kioto str., Kyiv, Ukraine, 02156

\section{Galina Tolok} \\ Department of hotel and restaurant business \\ Kyiv National University of Culture and Arts \\ 36 Konovaltsa str., Kyiv, Ukraine, 01133 \\ tga27@ukr.net
}

\footnotetext{
Abstract

The aim of the article is to study and to generalize technological properties of eggplant powder, produced by infrared drying at temperatures $50-60{ }^{\circ} \mathrm{C}$. The results of the conducted complex of studies reflect main technological and consumption properties of the received puree that plays an important role at creating new culinary products.
} 
So, for studying technological properties of food eggplant powder, there was considered the complex of base functional-technological properties of powder, produced by infrared drying.

For finding optimal conditions of rehydration of eggplant powders, there was studied the influence of such technological factors as: swelling ability; liquid; powder ratio; influence of the solvent temperature on renovation; renovation duration; degree of comminution of powders.

Main parameters that influence the renovation ability of dried eggplants are investigated and studied in the article. The results of the studies of technological properties of eggplant powders prove their high rehydration properties. It gives a possibility to use powders at producing different culinary products not only for enriching them with functional ingredients, but also for giving them new technological properties.

Based on the obtained results, there was elaborated and presented the new technological scheme of using renewed powders in food compositions.

Keywords: vegetable powders, eggplant powders, renovation ability, water-retaining ability, rheological parameters.

(C) Oksana Dzyundzya, Valentyna Burak, Alexander Averchev, Natalya Novikova,

DOI: 10.21303/2504-5695.2018.00723 Irina Ryapolova, Artem Antonenko, Tetiana Brovenko, Myroslav Kryvoruchko, Galina Tolok

\section{Introduction}

Eggplants are rather valuable raw material, but a season one [1-3]. One of ways of conservation of vegetable raw materials is drying in powders [4, 5]. The drying process allows to avoid a season character of eggplants consumption, to simplify operations for their culinary processing, to shorten a duration of the technological process of preparing dishes and to widen their assortment, to decrease areas of warehouses and production rooms, to create correspondent sanitary-hygienic conditions. Due to infrared drying, the time of thermal processing of the product shortens and maximal conservation of the nutrient composition is attained. Taking it into account, eggplant powder is a rather promising raw material for being used at enterprises of restaurant economy and food industry.

Eggplant powder is a new raw material, so it is necessary to establish main technological properties for further modeling new culinary products.

Eggplant powder corresponds to requirements, set to this type of raw materials by the content of toxic elements and by microbiological parameters $[4,6]$.

It must be noted, that the developed powder doesn't need additional conditions of storage, which term is 12 months.

At developing and manufacturing restaurant economy products, it is necessary to know main technological properties of raw materials $[7,8]$. So it is very important to study main characteristics of powders. One of criteria of estimating their quality is the rehydration ability. The renovation characteristic of a material depends on many factors, first of all, chemical composition of a raw material, its structure, physical-chemical properties and degree of changes, undergone by a product at drying, and influences the ready product's quality. The incorrect renovation can result in losses of valuable food materials, contained in powder as dry substances. The powder quality depends on an initial raw material, regimes of technological processing, conditions of storage and renovation.

The renovation ability of a material is characterized by a value of the swelling coefficient $\mathrm{C}_{\mathrm{s}}$ that indicates the relative decrease of a product mass after swelling and determines the ability to renew initial properties of a material at dehydration [7].

For determining optimal rehydration conditions for eggplant powders, there was studied the influence of the following technological factors:

1) Liquid:powder ratio;

2) Solvent temperature;

3) Renovation duration;

4) Powders comminution degree.

So, the aim of this work is to study and to generalize technological properties of eggplant powder, produced by infrared drying. The obtained experimental material allows to calculate the necessary amount of powder as a food supplement at creating recipes and fast food products and to determine time for preparing dishes. 


\section{Materials and methods}

The research object of this work is a food powder of eggplants, received by infrared drying. For producing it, there was chosen the middle-ripe variety of eggplants Diamond, technically ripe, planted in Bilozersky district (Kherson region, Veliky Kopany region, Ukraine). Fruits are characterized by high good parameters, flesh is light-green, with the dense consistence, without the expressed bitterness. Due to its good characteristics it is the most spread crop in the South of Ukraine.

For studying technological properties of eggplant food powder, obtained by infrared drying, there were determined the dispersibility of powders; swelling ability; influence of the solvent temperature on renovation; rheological parameters.

The comminution degree of eggplant powders was determined by sifting a product batch through a sieve and weighting a residue on it $[8,9]$. The amount of bound water was determined by the indicator refractometric method (Fig. 1, a) [10]. Rheological characteristics of eggplant powder were determined on Ostwald viscometers (Fig. 1, b) [11]. The density of the studied samples was determined volumetrically - by weighing $[12,13]$. The renovation ability of eggplant powders was determined by the method of B. V. Zozulevich $[8,9]$. Optimal regimes for powders renovation were chosen using the method of mathematical planning of an experiment [7-9].

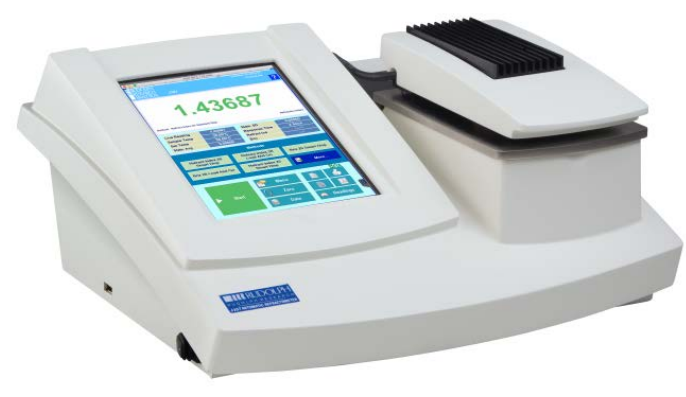

$a$

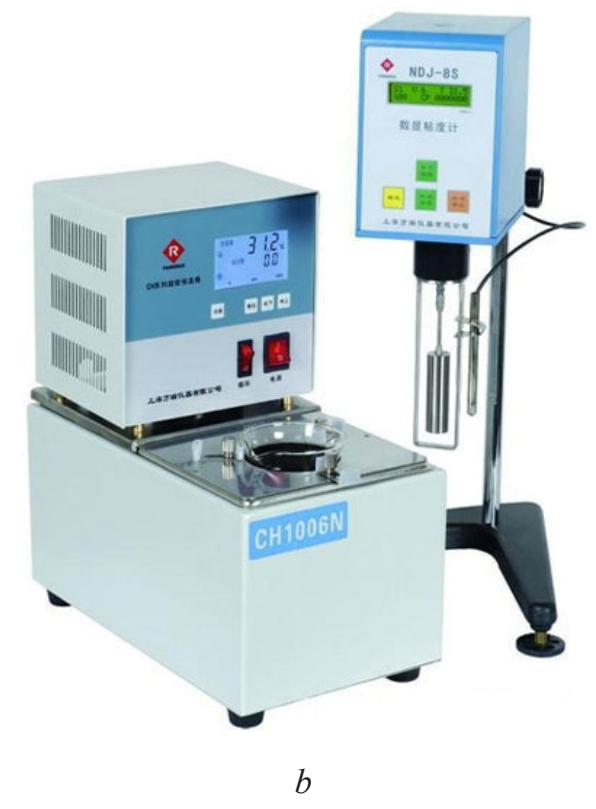

Fig. 1. Devices for the studies: $a$-digital refractometer Rudolph J157 (USA);

$b$ - Oswald viscometer (China)

\section{1. Experiments}

The ratio between liquid and powder was established by the method of selection of optimal compositions [9]. 
There was studied the renovation degree of powders in water before thermal processing. For getting puree, powders were renewed by the method of B.V. Zozulevich in interval 3,0 $10^{2} \ldots 1,8 \cdot 10^{3}$ with different hydromodules $[8,9]$. During the experiment there was studied the liquid and powder ratio in proportions 1:1,1:2,1:3,1:4,1:5,1:6. Puree of boiled eggplants was taken as a control.

For determining the solvent temperature influence of eggplant powder renovation, there was taken the liquid-powder ratio in proportions 1:2, 1:3, 1:4, 1:5, 1:6, renovation duration $10 \mathrm{~min}$, water temperature $20,40,60,80,100^{\circ} \mathrm{C}$, in all cases the dry powder mass was $10 \mathrm{~g}$. Dry soluble substances were determined by centrifuging. The research results are presented in table 1.

The water-retaining ability of eggplant powders was determined by the centrifuging method that provides hydration of the batch at the determined temperature and dispersity. The residue is centrifuged and dried. The ratio of evaporated water to the solid residue mass gives the value of water-retaining dependence. The time of the previous wetting, temperature, speed and time of centrifuging doesn't essentially influence the value of water-retaining ability.

\section{Results}

One of criteria of estimating the quality of dry products is the ability to swelling that depends on the chemical composition and water-retaining ability of powder. It was established, that dispersity influences the value of the water-retaining ability. At dispersity $>0,315 \mathrm{~mm}=80 \%$, $>0,25 \mathrm{~mm}=60 \%, 0,16 \mathrm{~mm}=56 \%$. Despite the obtained data, it is most optimal to study powders with dispersity $0,25 \mathrm{~mm}$.

Optimal conditions of powder renovation were chosen depending on such parameters as rehydration duration, hydromodule $(1: 2,1: 3,1: 4,1: 5,1: 6)$, solvent temperature $(20,40,60,80$, $100{ }^{\circ} \mathrm{C}$ ) (Fig. 2).

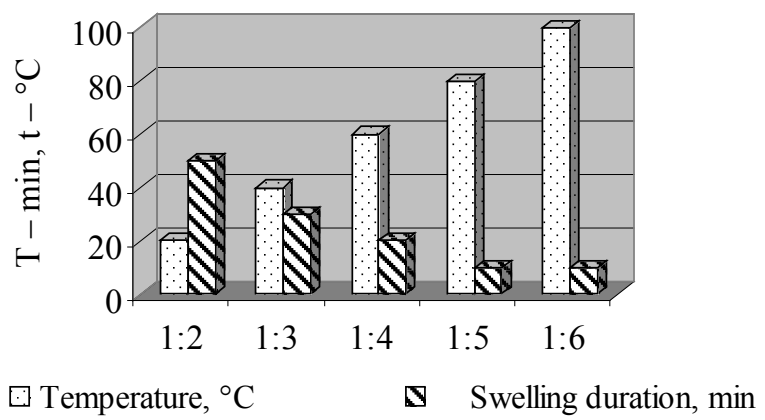

Fig. 2. Dependence of temperature and dissolution duration of eggplant powders

The important role at powders renovation is played by the temperature of water, taken for hydration. It was established that the powder has the high swelling and renovation ability, and the speed depends on the water temperature and dispersity.

It was experimentally established, that powder with sizes of particles less $0,25 \mathrm{~mm}$ has a puree-like mass, like in the control. Powders of different fractions were left for 24 hours for watering, as a result the amount of water, taken by dry eggplants with different comminution degrees, was practically equal.

It was established, that at the beginning of the process the water-absorbing ability is higher than in a certain time interval after the beginning. In first $3 \cdot 10^{2} \ldots 6 \cdot 10^{2} \mathrm{~s}$ a certain amount of water is absorbed by powders with the further decrease of the absorption speed. Losses of soluble substances reach maximum in $6,0 \cdot 10^{2}-9,0 \cdot 10^{2} \mathrm{~s}$ the further increase of the rehydration duration (to $1,8 \cdot 10^{3} \mathrm{~s}$ ) is accompanied by the increase of the water-absorbing ability of powders and it becomes the same as at the beginning in first $3,0 \cdot 10^{2}-6,0 \cdot 10^{2} \mathrm{~s}$. At the same time diffusion processes finish, and there is no increment of the amount of extracted substances. There is observed its decrease at the expanse of absorption by swelled powder particles.

The essential increase of the rehydration ability in powders is observed at temperatures less $60{ }^{\circ} \mathrm{C}$, at the further water temperature increase it remains practically the same (Table 1). 
Table 1

Influence of solvent temperature on renovation of eggplant powders

\begin{tabular}{|c|c|c|c|}
\hline Hydromodule/temperature,${ }^{\circ} \mathrm{C}$ & Swelling coefficient, $\%$ & Dry soluble substances, $\%$ & Renovation ability, \% \\
\hline \multicolumn{4}{|c|}{$1: 2$} \\
\hline 20 & $2,7 \pm 0,13$ & $7,2 \pm 0,36$ & $36,7 \pm 1,84$ \\
\hline 40 & $3,5 \pm 0,17$ & $7,9 \pm 0,40$ & $63,2 \pm 3,16$ \\
\hline 60 & $3,8 \pm 0,18$ & $8,3 \pm 0,42$ & $86,0 \pm 4,30$ \\
\hline 80 & $3,8 \pm 0,18$ & $8,5 \pm 0,43$ & $86,2 \pm 4,31$ \\
\hline 100 & $3,8 \pm 0,18$ & $8,5 \pm 0,43$ & $86,3 \pm 4,32$ \\
\hline \multicolumn{4}{|c|}{$1: 3$} \\
\hline 20 & $3,4 \pm 0,17$ & $7,8 \pm 0,39$ & $42,0 \pm 2,10$ \\
\hline 40 & $4,0 \pm 0,20$ & $8,5 \pm 0,43$ & $78,4 \pm 3,93$ \\
\hline 60 & $4,5 \pm 0,23$ & $9,5 \pm 0,48$ & $94,0 \pm 4,70$ \\
\hline 80 & $4,7 \pm 0,24$ & $9,6 \pm 0,48$ & $94,5 \pm 4,73$ \\
\hline 100 & $4,8 \pm 0,24$ & $9,6 \pm 0,48$ & $94,5 \pm 4,73$ \\
\hline \multicolumn{4}{|c|}{$1: 4$} \\
\hline 20 & $3,8 \pm 0,18$ & $7,6 \pm 0,38$ & $39,8 \pm 1,99$ \\
\hline 40 & $4,0 \pm 0,20$ & $8,6 \pm 0,43$ & $64,9 \pm 3,25$ \\
\hline 60 & $4,7 \pm 0,23$ & $9,6 \pm 0,48$ & $92,9 \pm 4,65$ \\
\hline 80 & $4,7 \pm 0,23$ & $9,5 \pm 0,48$ & $93,1 \pm 4,65$ \\
\hline 100 & $4,7 \pm 0,23$ & $9,5 \pm 0,48$ & $92,9 \pm 4,65$ \\
\hline \multicolumn{4}{|c|}{$1: 5$} \\
\hline 20 & $3,8 \pm 0,18$ & $7,4 \pm 0,37$ & $38,0 \pm 1,90$ \\
\hline 40 & $4,1 \pm 0,20$ & $8,2 \pm 0,42$ & $62,5 \pm 3,13$ \\
\hline 60 & $4,7 \pm 0,23$ & $8,6 \pm 0,43$ & $83,0 \pm 4,15$ \\
\hline 80 & $4,7 \pm 0,23$ & $8,7 \pm 0,43$ & $83,1 \pm 4,16$ \\
\hline 100 & $4,7 \pm 0,23$ & $8,6 \pm 0,43$ & $83,1 \pm 4,16$ \\
\hline \multicolumn{4}{|c|}{$1: 6$} \\
\hline 20 & $3,4 \pm 0,17$ & $7,2 \pm 0,36$ & $36,4 \pm 1,82$ \\
\hline 40 & $3,8 \pm 0,18$ & $8,1 \pm 0,41$ & $65,6 \pm 3,23$ \\
\hline 60 & $4,4 \pm 0,22$ & $8,6 \pm 0,43$ & $82,3 \pm 4,12$ \\
\hline 80 & $4,3 \pm 0,22$ & $8,5 \pm 0,43$ & $82,4 \pm 4,12$ \\
\hline 100 & $4,2 \pm 0,21$ & $8,5 \pm 0,43$ & $82,3 \pm 4,12$ \\
\hline
\end{tabular}

Note: *-Difference is reliable, $p<0,05$

The analysis of the obtained data demonstrated that the swelling coefficient of eggplant powders at temperature $20^{\circ} \mathrm{C}$ in the experiments with equal renovation durations has a tendency to the growth with increasing the water-powder ratio.

It was established (Table 2), that at the powder-water ratio as 1:2 the swelling coefficient was $2,7 \%$, and at $1: 4$ and $1: 5-3,8 \%$. 
At the temperature increase to $40{ }^{\circ} \mathrm{C}$ and $60{ }^{\circ} \mathrm{C}$ there is traced the same regularity. Namely: at $1: 2-3,5 \%$ and $3,8 \%$ and at $1: 5-4,1 \%$ and $4,7 \%$.

At the rehydration duration increase from $3,0 \cdot 10^{2} \mathrm{~s}$ to $1,8 \cdot 10^{3} \mathrm{~s}$ and water temperature increase to $60{ }^{\circ} \mathrm{C}$ the water-retaining ability of eggplant powder puree increases, that is testified by the ability of restored powder to retain moisture after centrifuging. At the renovation water temperature increase to $80^{\circ} \mathrm{C}$, the powder ability to retain moisture decreases.

Table 2

Changes of rheological characteristics of renewed eggplant powders depending on rehydration duration

\begin{tabular}{|c|c|c|c|}
\hline Thermal processing duration, $10^{2} \mathrm{~s}$ & Viscosity, Pa·s & Fluidity $1^{2} \mathrm{~Pa} \cdot \mathrm{s}^{-1}$ & Dynamic limit of fluidity $\mathrm{Pa} \cdot \mathrm{s}$ \\
\hline $3,0 \cdot 10^{2}$ & $1,80 \pm 0,7$ & $7,60 \pm 0,7$ & $5,10 \pm 0,8$ \\
\hline $6,0 \cdot 10^{2}$ & $2,48 \pm 0,9$ & $8,0 \pm 0,6$ & $4,7 \pm 0,8$ \\
\hline $12,0 \cdot 10^{2}$ & $2,48 \pm 0,9$ & $8,2 \pm 0,4$ & $4,7 \pm 0,7$ \\
\hline $18,0 \cdot 10^{2}$ & $3,1 \pm 0,7$ & $8,3 \pm 0,4$ & $4,3 \pm 0,7$ \\
\hline
\end{tabular}

Note: * Difference is reliable, $p<0,05$

At powders renovation there takes place extraction of soluble substances, mainly due to diffusion. In all cases losses of soluble substances reach maximum at $6,0 \ldots 9,0 \cdot 10^{2} \mathrm{~s}$. The further rehydration duration increase to $1,8 \cdot 10^{3} \mathrm{~s}$ and more results in the water-absorbing ability decrease.

The most important parameter is a rehydration duration. As far as viscosity gains its maximal value at $60{ }^{\circ} \mathrm{C}$, for studying the influence of the swelling duration on powders renovation, just these samples with hydromodules 1:3, 1:4, 1:5, 1:6 were taken. Renovation was realized during 3,0-18,0·10² s. It was established, that the viscosity increase is observed in first $6,0 \ldots 9,0 \cdot 10^{2} \mathrm{~s}$. The swelling time increase to $1,8 \cdot 10^{3} \mathrm{~s}$ doesn't essentially influence the viscosity of obtained puree and reaches its maximal value at the temperature from $45^{\circ} \mathrm{C}$ to $60^{\circ} \mathrm{C}$ and at hydromodule $1: 3$. It was established, that the viscosity increase takes place during $9,0 \cdot 10^{2} \mathrm{~s}$, the essential amount of pectins results in gelatinization of obtained puree with hydromodules 1:4, 1:3. As a result of renovation there forms gel that gives the correspondent consistence to puree of powders. The rational conditions for rehydration is the liquid temperature less $60^{\circ} \mathrm{C}$, swelling duration $6,0 \ldots 9,0 \cdot 10^{2} \mathrm{~s}$, with powder-liquid ratio 1:3, 1:4.

For the quality estimation of restored powder, there were determined rheological properties in the prepared samples (viscosity, fluidity, dynamic limit of fluidity, taking into account the fact that puree is a disperse system (Table 3).

Table 3

Rheological parameters of restored eggplants powders

\begin{tabular}{cccccccc}
\hline \multirow{2}{*}{ Parameters } & Puree of eggplants & \multicolumn{5}{c}{ Puree of eggplant powder (hydromodule) } \\
\cline { 3 - 8 } & & $\mathbf{1 : 1}$ & $\mathbf{1 : 2}$ & $\mathbf{1 : 3}$ & $\mathbf{1 : 4}$ & $\mathbf{1 : 5}$ & $\mathbf{1 : 6}$ \\
\hline Dynamic viscosity, Pa·s & 13,60 & 18,40 & 15,60 & 12,70 & 11,98 & 8,62 & 5,25 \\
Dynamic limit of fluidity, 10² $\mathrm{Pa}$ & 4,66 & 7,20 & 5,25 & 4,70 & 4,44 & 1,92 & 1,80 \\
Fluidity, 102 $\mathrm{Pa} \cdot \mathrm{s}^{-1}$ & 7,91 & 4,60 & 6,49 & 8,20 & 9,36 & 12,81 & 16,73 \\
Plastic viscosity, Pa·s & 3,20 & 0,78 & 1,44 & 2,48 & 3,30 & 4,83 & 6,06 \\
Plasticity coefficient & 0,97 & 0,60 & 0,73 & 0,89 & 0,92 & 1,27 & 2,03
\end{tabular}

At powder-water ratio 1:1 the dynamic viscosity of prepared powder is rather high $18,4 \mathrm{~Pa} \cdot \mathrm{s}$, that is by $26 \%$ more than one of the control sample. The hydromodule increase to $1: 3$ brings the dynamic viscosity of restored powders close to indices of fresh puree. So, the dynamic viscosity of obtained renewed powder is by $6 \%$ less than the control at the hydromodule 1: 3 . 
At the further hydromodule increase to 1:5 and 1:6 the dynamic viscosity index decreases by $36 \%$ and $61 \%$ respectively. The analogous changes take place also with other rheological indices of restored powders.

The obtained data testify to high rehydration properties of developed powder that is an important factor at creating culinary products.

Based on the obtained data, there was elaborated the general scheme of eggplant powders renovation (Fig. 3).

\begin{tabular}{|c|c|c|c|c|}
\hline $\begin{array}{l}\text { Eggplant } \\
\text { powder }\end{array}$ & Sifting & $\begin{array}{l}\text { Hydration } \\
1: 3 \tau=6,0 \cdot 10^{2} \mathrm{~s}\end{array}$ & $\begin{array}{l}\text { Restored } \\
\text { powder }\end{array}$ & $\begin{array}{l}\text { Use in food } \\
\text { compositions }\end{array}$ \\
\hline
\end{tabular}

Fig. 3. General technological scheme of using restored eggplant powders in food compositions

The advantage of developed powders is the high renovation level, comfort use, long storage life without special conditions. Their use gives a possibility to create biologically active complexes for providing physiologically full value dishes that allow to influence organoleptic parameters, structural-mechanical properties of ready products essentially.

The perspective of further studies is to define ways of further use of eggplant powders and creation of culinary products, based on them. Determination and study of their influence on structural-mechanical properties and chemical composition of developed products defines a way of further studies.

\section{Conclusions}

1. The methods and methodologies for studying technological properties of eggplant powders were determined.

2. The optimal conditions for powders rehydration as liquid temperature less $60{ }^{\circ} \mathrm{C}$, swelling duration $6,0 \ldots 9,0 \cdot 10^{2} \mathrm{~s}$, with liquid-powder ratio $1: 3,1: 4$ were determined.

3 . Based on the obtained results, the general technological scheme of using eggplant restored powders in food compositions was elaborated.

4. The research results demonstrated the high degree of powders renovation. It gives a possibility to use powders at producing different culinary products as a functional supplement not only for enriching them with functional ingredients, but also for giving them new technological properties. They are able to improve structural-mechanical properties and outlook of ready products.

5. Scientific studies as to possibilities of using eggplant powders in technologies of culinary dishes and the influence of the offered supplements on the food and biological value of products on their base are expedient.

\section{References}

[1] Gurbuz, N., Uluisik, S., Frary, A., Frary, A., Doganlar, S. (2018). Health benefits and bioactive compounds of eggplant. Food Chemistry, 268, 602-610. doi: http://doi.org/10.1016/j.foodchem. 2018.06.093

[2] Makrogianni, D. I., Tsistraki, A., Karapanos, I. C., Passam, H. C. (2017). Nutritional value and antioxidant content of seed-containing and seedless eggplant fruits of two cultivars grown under protected cultivation during autumn-winter and spring-summer. Journal of the Science of Food and Agriculture, 97 (11), 3752-3760. doi: http://doi.org/10.1002/jsfa.8238

[3] Djouadi, A., Lanez, T., Boubekri, C. (2016). Evaluation of antioxidant activity and polyphenolic contents of two South Algerian eggplants cultivars. Journal of Fundamental and Applied Sciences, 8 (2), 223-231. doi: http://doi.org/10.4314/jfas.v8i2.3

[4] Sniezhkin, Yu. F., Petrova, Zh. O., Paziuk, V. M. (2016). Energy efficient heat technology of production functional food powders. Vinnytsia: VNAU, 456. 
[5] Ibrahim, T. A., Omosuli, S. V., Oloye, D. A. (2016). Effect of Microwave Drying on Chemical Composition of Some Leafy Vegetables. Research \& Reviews. Journal of Food Science and Technology, 5 (3), 18-21.

[6] Aydogdu, A., Sumnu, G., Sahin, S. (2015). Effects of Microwave-Infrared Combination Drying on Quality of Eggplants. Food and Bioprocess Technology, 8 (6), 1198-1210. doi: http://doi.org/10.1007/ s11947-015-1484-1

[7] Snezhkin, Yu. F., Shapar', R. A., Petrova, Zh. A., Dabizha, N. A. (2002). Ocenka kachestva sushenyh produktov po vosstanavlivaemosti [Evaluation of the quality of dried products on the recoverability]. Naukovi praci ODAHT [Scientific works ONHTT'S], 23, 172-175.

[8] Shapar, R. O. (2004) Intensifikaciya procesiv sushinnya roslinnih pektinovmisnih materialiv [Intensification of drying process of plant pectin containing materials]. Kyiv: ITTF.

[9] Petrova, Zh. O. (2013) Stvorennya energoefektivnih teplotekhnologii virobnictva funkcional'nih harchovih poroshkiv [Creation of energy-efficient thermal technologies for the production of functional hawas powders]. Kyiv: ITTF.

[10] Mank, V. V., Volovyk, L. S., Kovalevska, E. I. et. al. (2001). Koloyidna khimiya: Metodychni vkazivky do vykonannya laboratornykh robit [Colloidal chemistry: Methodical instructions for laboratory work]. Kyiv: UDUKHT, 41.

[11] Goral'chuk, A. B., Pivovarov, P. P., Grinchenko, O. O., Pogozhih, M. I., Polevich, V. V., Gurs'kii, P. V. (2006). Reologichni metodi doslidzhennya sirovini i harchovih produktiv ta avtomatizaciya rozrahunkiv reologichnih harakteristik [Rheological research methods of raw materials and food products and automation of calculation of rheological characteristics]. Kharkiv, 63.

[12] Skuratovskaia, O. D. (2001). Kontrol kachestva produktsyy fyzyko-khymycheskymy metodamy [Controlling the quality of products used in the fyzyko-khymycheskymy method]. Moscow: Vydavnytstvo DeLy prynt, 141

[13] Lure, I. S. (2001). Tekhnokhimichnyy kontrol u kondyterskiy promyslovosti [Technochemical control in the confectionery industry]. Kyiv: Kolos, 352. 